\title{
Capsule-Endoscopic Findings of Ulcerative Colitis Patients
}

\author{
Takuma Higurashi $^{a}$ Hiroki Endo ${ }^{a}$ Masato Yoneda ${ }^{a}$ Kunihiro Hosono ${ }^{a}$ \\ Eiji Sakai $^{a}$ Hirokazu Takahashi ${ }^{a}$ Masahiko Inamoria Shiori Uchiyamab \\ Takuto Kojima $^{\text {b Kenichi Kawana }}{ }^{b}$ Yutaka Natsumeda ${ }^{c}$ Hajime Nagase $^{b}$ \\ Atsushi Nakajima ${ }^{a}$ \\ ${ }^{a}$ Division of Gastroenterology, Yokohama City University School of Medicine, ${ }^{b}$ Department of Gastroenterology, \\ Yokohama Rosai Hospital, and ' Department of Clinical Research, Yokohama City University School of Medicine, \\ Yokohama, Japan
}

\section{Key Words}

Capsule endoscopy · Small intestine $\cdot$ Ulcerative colitis as compared with the healthy volunteers. It was concluded that UC, a chronic inflammatory bowel disease, can also involve the small bowel.

Copyright ๑ 2011 S. Karger AG, Basel

\begin{abstract}
Background/Aims: Ulcerative colitis (UC) is a chronic inflammatory bowel disease characterized by diffuse mucosal inflammation, traditionally regarded as being limited to the colorectum. Although several gastroduodenal lesions have also been reported recently in cases of UC, in general, smallbowel lesions in UC are believed to be extremely rare. The aim of this study was to examine the small bowel by capsule endoscopy in patients with UC. Methods: The study was conducted in 23 well-documented UC patients and 23 control volunteers. The frequency of small-bowel lesions, the number of small-bowel lesions per patient and the capsule endoscopy score were comparatively evaluated between the two groups. Results: Of the 23 UC patients, 13 (57\%) showed small-bowel lesions, and 8 (35\%) had erosions. There were significant differences in the frequency of the smallbowel lesions $(p<0.001)$ and erosions $(p=0.009)$ between the two groups. The capsule endoscopy score was correlated with the UC disease activity index $(r=0.718, p<0.001)$. Conclusions: This is the first capsule-endoscopic study conducted to examine the small-bowel involvement in UC patients
\end{abstract}

\section{Introduction}

Ulcerative colitis (UC) is a chronic inflammatory bowel disease characterized by diffuse mucosal inflammation, mainly of the colorectum, and its etiology and pathogenesis still remain poorly understood. UC is traditionally regarded as predominantly involving the rectum and spreading proximally, generally sparing the alimentary canal proximal to the ileocecal valve. However, gastroduodenal lesions have also been reported recently in cases of UC, such as backwash ileitis and postcolectomy pouchitis [1-6]. Furthermore, some investigators have proposed that since UC is also commonly associated with extraintestinal involvement, such as of the biliary tract, anterior chamber of the eye and synovium, it should be considered as a systemic disease and not as a localized colonic disease [7-9]. Data on the small-bowel abnormalities in UC are limited, owing to the lack of availability of an optimum tool for exploring the entire length of the

\section{KARGER}

Fax +4161306 1234 E-Mail karger@karger.ch www.karger.com
(C) 2011 S. Karger AG, Basel

0012-2823/11/0844-0306\$38.00/0

Accessible online at:

www.karger.com/dig
Hiroki Endo

Division of Gastroenterology

Yokohama City University School of Medicine

3-9 Fuku-ura, Kanazawa-ku, Yokohama 236-0004 (Japan)

Tel. +81 45787 2640, E-Mail endo1978@yokohama-cu.ac.jp 
Table 1. Characteristics of the UC patients and healthy volunteers in this study

\begin{tabular}{|c|c|c|c|}
\hline & UC group & Control group & $\mathrm{p}$ value \\
\hline Number of subjects & 23 & 23 & \\
\hline $\operatorname{Sex}(M: F)$ & $13: 10$ & $14: 9$ & 0.764 \\
\hline Mean age $\pm S D$, years & $42.9 \pm 18.0$ & $40.0 \pm 15.4$ & 0.565 \\
\hline Median duration of UC, months (range) & $78(1-292)$ & & \\
\hline Extent of UC (pancolitis:left-sided colitis:proctosigmoiditis) & $12: 7: 4$ & & \\
\hline \multicolumn{4}{|l|}{ DAI } \\
\hline$(0-2)$ & 6 & & \\
\hline$(3-6)$ & 10 & & \\
\hline$(7-10)$ & 7 & & \\
\hline$(11-12)$ & 0 & & \\
\hline \multicolumn{4}{|l|}{ UC treatment } \\
\hline No medication & \multicolumn{3}{|c|}{13 (includes 8 first-attack UC) } \\
\hline Prednisolone & \multicolumn{3}{|c|}{0} \\
\hline Mesalazine & \multicolumn{3}{|l|}{10} \\
\hline
\end{tabular}

DAI $=$ Disease activity index according to Sutherland's criteria.

small-bowel. While some reports of postcolectomy pouchitis have been published $[3-5,10]$, there are no reports, until date, of frequency and nature of small-bowel involvement in unoperated UC patients. Capsule endoscopy is a newly developed tool with a high diagnostic yield for small-bowel pathologies $[11,12]$. In view of the scarcity of information on the small-bowel involvement in UC, we conducted the present capsule-endoscopic study to evaluate the frequency and nature of small-bowel involvement in UC patients. The aim of this pilot study was to investigate the frequency and characteristics of smallbowel lesions in patients with UC.

\section{Subjects and Methods}

This study was a prospective, endoscopist-blinded, case-control pilot study conducted in UC patients and healthy volunteers; the study was conducted in accordance with the Declaration of Helsinki. Approval for the study was obtained from the Ethics committee of Yokohama Rosai Hospital, Yokohama, Japan. Written informed consent for participation in the study was obtained from all the UC patients and volunteers.

This study was conducted between June 2009 and December 2010 at Yokohama Rosai Hospital. UC patients and volunteers were recruited by putting up a poster at the hospital. The exclusion criteria were shown later. A total of 23 patients with well-documented UC (UC group) and 23 healthy volunteers (Control group) matched for age and sex were enrolled in this study. Matching was performed by an independent person unaware of the objective of this study. The profiles of the enrolled patients and volunteers are shown in table 1 . The diagnosis of UC was confirmed in all cases using widely accepted clinical, radiologic, endoscopic and patho- logic criteria $[13,14]$. All patients were confirmed to be fecal culture-negative and cytomegalovirus antigenemia-negative. None of the patients or volunteers had a history of treatment with nonsteroidal anti-inflammatory drugs (NSAIDs) or aspirin within 3 months prior to the start of the study. None of the subjects had a history of chronic alcohol consumption (>20 g alcohol/day), or any history of abdominal surgery. None of the volunteers had any symptoms (e.g. diarrhea or abdominal pain), any history of use of antiulcer medications (i.e. histamine $\mathrm{H} 2$ receptor antagonists, proton pump inhibitors, or misoprostol), or a history of cardiovascular, respiratory or gastrointestinal diseases.

The following clinical data of the enrolled patients were collected at the time of the capsule-endoscopic examination: age, sex, disease duration, location of the colonic lesions, disease activity, and medication history. Colonoscopy was performed within 1 month of enrollment. The colitis was classified into pancolitis, left-sided colitis (defined as disease extending up to the splenic flexure) or proctosigmoiditis, according to the location of the lesions. Disease activity was determined both clinically and by colonoscopy. The clinical disease activity was graded based on the clinical features and endoscopic mucosal appearances, in accordance with the criteria for determination of the Sutherland Index (disease activity index: DAI) [15]. Two physicians independently graded the endoscopic findings and DAI at the time of enrollment. A follow-up capsule endoscopy shall be performed in previously untreated patients with first-attack UC after remission is achieved (fig. 1).

\section{Capsule Endoscopy Procedure}

All the video images were reviewed using the Pill Cam SB and SB2 capsule endoscopy system (Given Imaging Ltd., Yokneam, Israel). The capsule-endoscopic examination was performed after the patients had fasted for $12 \mathrm{~h}$. Fluids and light meals were allowed 2 and $4 \mathrm{~h}$, respectively, after the capsule had been swallowed. Both the patients and volunteers were free to leave the hospital, with instructions to return within the 8-hour study period, 


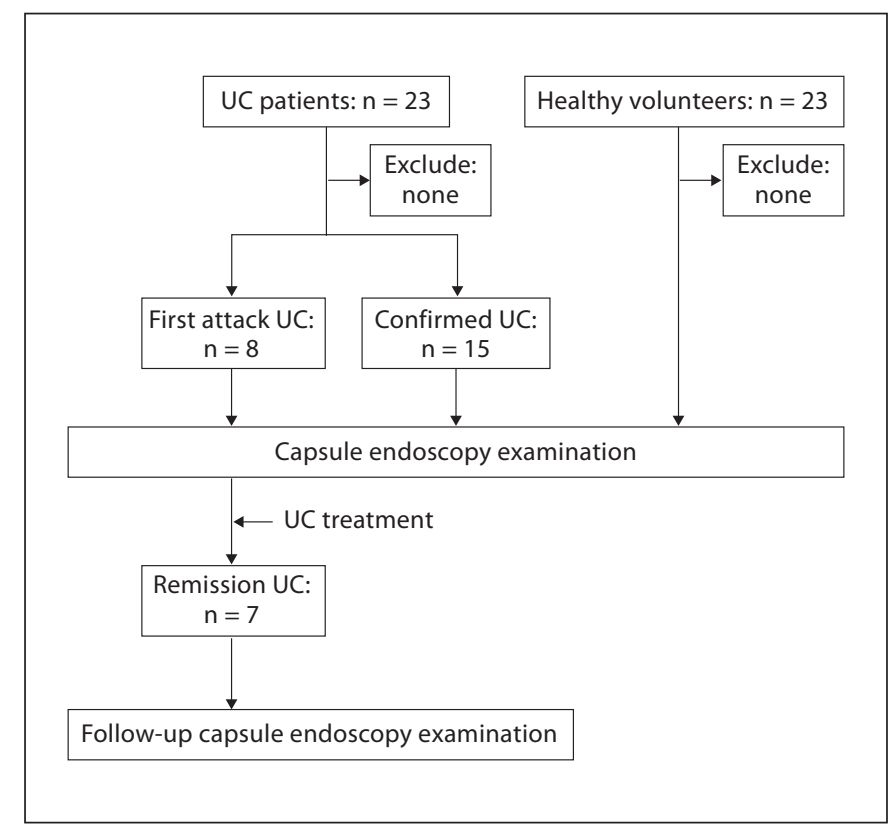

Fig. 1. Flow diagram of this study. small-bowel transit time into three equal time allotments. The total score was the sum of the score for the highest tertile plus the stenosis score. The results were classified into three categories by the final numerical score: normal or clinically insignificant change (score <135), mild change (score between 135 and 790), and moderate or severe change (score $\geq 790$ ).

If the judgment regarding the capsule-endoscopic findings or capsule endoscopy score assigned by the two endoscopists was different, the judgment of the preliminary endoscopist was used.

\section{Statistical Analyses}

The results were presented as mean or median $( \pm S D$ or range) for quantitative data, and as frequency (percentage) for categorical data. Categorical data were analyzed using the $\chi^{2}$ test or Fisher's exact test. The age, number of small-bowel erosions and ulcers, and the total number of small-bowel lesions were compared between the UC group and the control group by Student's t test. The capsule endoscopy score was also compared between the UC group and the control group, and the statistical significance of any differences was assessed by Mann-Whitney's U test. Pearson's product moment correlation coefficient ( $r$ ) was calculated to explore possible correlations between the capsule endoscopy score and the DAI, capsule endoscopy score and the score for the colonic appearance of the mucosa estimated for calculation of the DAI. $\mathrm{p}<0.05$ was considered indicative of statistical significance.

\section{Results}

digital information was downloaded from the recorder into the computer and the images were analyzed using the proprietary RAPID software. No bowel preparation procedure, such as administration of polyethylene glycol solution or sodium phosphate, was used.

\section{Data Analysis}

Two independent investigators who were blinded to the group allocation of the patients/volunteers separately reviewed the data obtained from each of the capsule-endoscopic examinations. The small-bowel lesions were classified in severity into three types; reddened lesions, erosions, and ulcers. Reddened lesions such as reddened folds, erythema/edema and petechiae were grouped into a single category. Examples of typical reddened lesions are shown in figure 2a. Superficial white lesions with surrounding erythema were characterized as erosions. Examples of typical erosions are shown in figure $2 \mathrm{~b}$. White lesions within a crater and with surrounding erythema were classified as ulcers. An example of a typical ulcer is shown in figure $2 c$. The finding of diffuse small-bowel ulcers or multiple ulcers $(>3)$ on capsule-endoscopic examination was considered being diagnostic of Crohn's disease, as described in a previous report $[16,17]$. Then, the distribution of the small-bowel lesions was analyzed. The small bowel was divided into 3 equal segments (proximal, middle and distal) on the basis of the small-bowel transit time in each subject (see below for detailed definition of the transit time). Furthermore, we assigned the capsule endoscopy score for the small-bowel mucosal inflammatory changes in order to strengthen the validity of our results [18]. This scoring index was based on three capsule-endoscopic variables: villous appearance, ulceration, and stenosis. The mucosal inflammatory changes were assessed in tertiles, dividing the
There were no examination-related complications in this study. Passage of the capsule with the stool within 2 weeks was confirmed in all the patients and volunteers (if natural passage of the capsule was not witnessed by the patient, an abdominal X-ray was obtained 14 days after the examination to confirm passage of the capsule). None of the subjects developed any adverse symptoms during the examination. In all the patients and volunteers, the capsule reached the cecum within the recording time.

\section{Capsule-Endoscopic Findings in the Two Groups}

No ulcers were seen in either group, and none of the UC patients had capsule-endoscopic findings consistent with the diagnosis of Crohn's disease.

The percentages of subjects with positive capsule-endoscopic findings (reddish lesions and erosions) in the two groups are presented in figure 3. Small-bowel lesions (reddened lesions and/or erosions) were noted in 13 of the 23 patients (57\%) of the UC group, and 2 of the 23 volunteers (7\%) of the control group. A statistically significant difference was observed in the frequency of small-bowel lesions between the two groups $(\mathrm{p}<0.001)$. Erosions were seen in 8 patients (35\%) of the UC group and 1 volunteer (4\%) of the control group. A statistically 

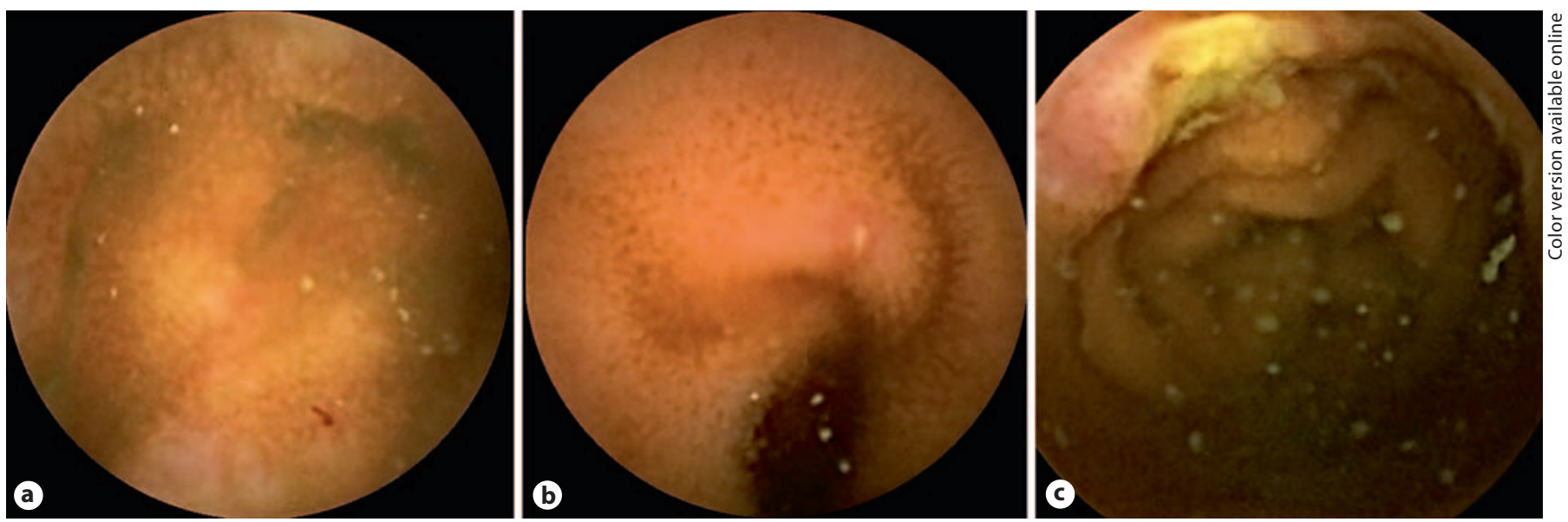

Fig. 2. a Example of a typical reddened lesion. b Example of a typical erosion. c Example of a typical ulcer.

significant difference was observed in the frequency of small-bowel erosions between the two groups $(\mathrm{p}=0.009)$. A representative erosion in the UC group is shown in figure $4 a, b$.

\section{Comparison of the Number of Small-Bowel Lesions}

between the Two Groups

There was a significant difference in the total number of small-bowel lesions (reddened lesions and erosions) per subject between the UC group (mean $5.0 \pm$ 6.4 ) and the control group (mean $0.1 \pm 0.5 ; \mathrm{p}<0.001$ ). Furthermore, there was a statistically significant difference in the number of erosions per subject between the UC group (mean $1.3 \pm 2.6$ ) and the control group (mean $0.0 \pm 0.2 ; \mathrm{p}=0.029$ ). The data are shown in detail in figure $5 \mathrm{a}, \mathrm{b}$.

\section{Distribution of the Small-Bowel Lesions in the UC \\ Patients}

In the UC group, a total of 115 small-bowel lesions (85 reddened lesions and 30 erosions) were found. The distribution of the small-bowel lesions was as follows (fig. 6a, b): 28 of the 115 small-bowel lesions (24\%) were located in the proximal part, $40(35 \%)$ in the middle part, and 47 $(41 \%)$ in the distal part of the small intestine. Six of the 30 erosions (20\%) were located in the proximal part, $9(30 \%)$ in the middle part, and 15 (50\%) in the distal part of the small intestine. When analyzed according to the location in the small bowel, the frequency of erosions and smallbowel lesions tended to increase with progression towards the distal intestine.

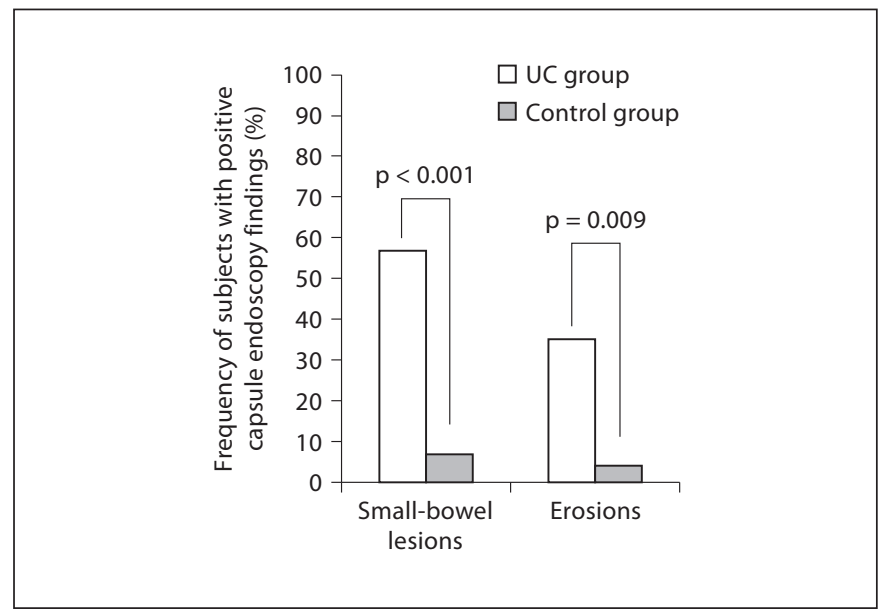

Fig. 3. Proportion of subjects with positive capsule-endoscopic findings in the two groups.
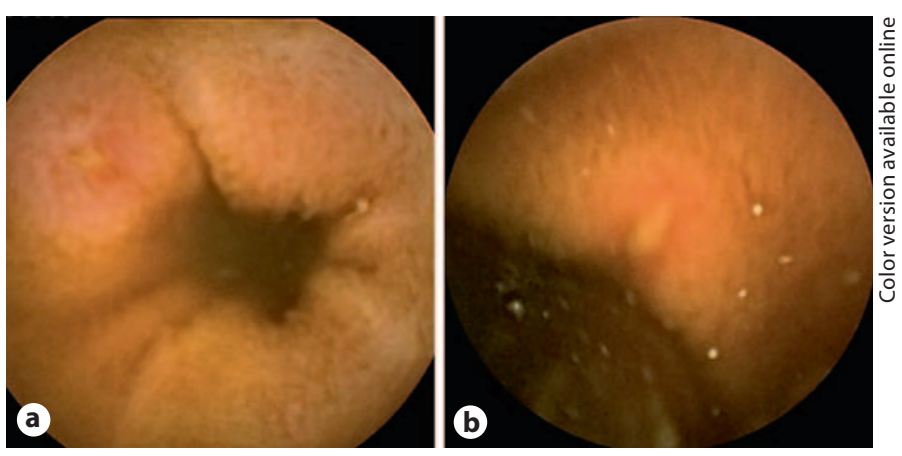

Fig. 4. Representative erosions in the UC group.

Digestion 2011;84:306-314 309 


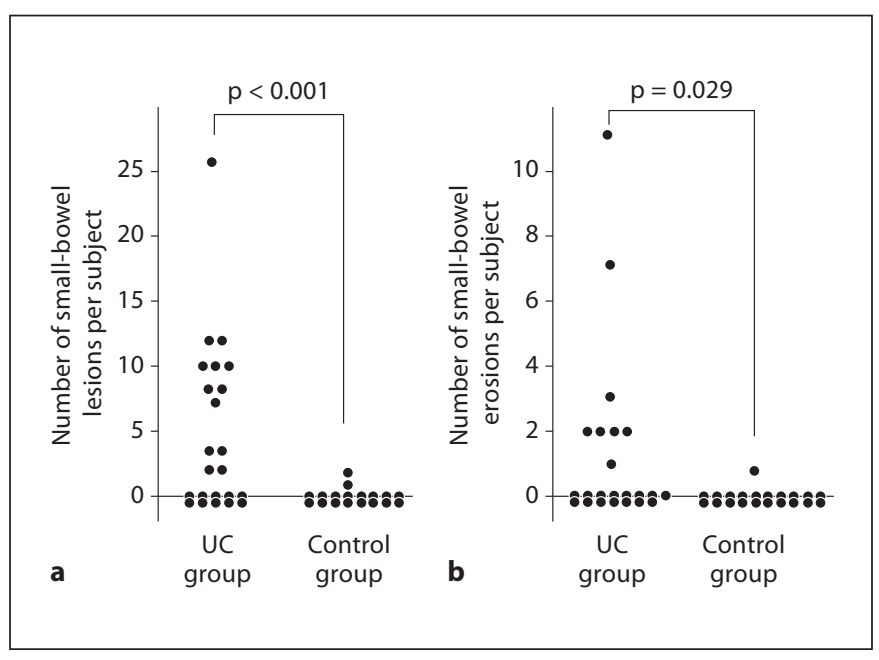

Fig. 5. a Comparison of the number of small-bowel lesions (reddened lesions and erosions). A statistically significant difference in the total number of small-bowel lesions per subject was noted between the UC group (mean $5.0 \pm 6.4$ ) and the control group (mean $0.1 \pm 0.5 ; \mathrm{p}<0.001$ ). b Comparison of the number of small-bowel erosions. A statistically significant difference in the total number of small-bowel erosions per subject was noted between the UC group (mean $1.3 \pm 2.6$ ) and the control group (mean $0.0 \pm 0.2 ; \mathrm{p}=0.029$ ).

Comparison of the Capsule Endoscopy Score for

Small-Bowel Mucosal Inflammatory Changes between the Two Groups

The capsule endoscopy score for the small-bowel mucosal inflammatory changes are shown in table 2 . In the control group, the findings in all the volunteers were categorized as 'normal' or 'clinically insignificant change (score <135)'. On the other hand, in the UC group, 9 of the 23 UC patients were classified as showing 'mild change (135 $\leq$ score < 790)' in the small-bowel mucosa, while the remaining were categorized as normal. None of the subjects in either group in this study showed 'moderate or severe change'. There was a statistically significant difference in the proportion of subjects showing 'mild change' between the two groups (UC group 39\% vs. control group $0 \% ; \mathrm{p}=0.015)$. The median capsule endoscopy score in the UC group was significantly higher than that in the control group (UC group $112(0-654)$ vs. control group $0(0-112) ; \mathrm{p}<0.001)$.

Furthermore, to examine the correlation between the small-bowel inflammatory changes and the UC disease activity, we calculated the capsule endoscopy score and the DAI (fig. 7a, b). A significant correlation was observed between the capsule endoscopy score and the DAI $(r=$

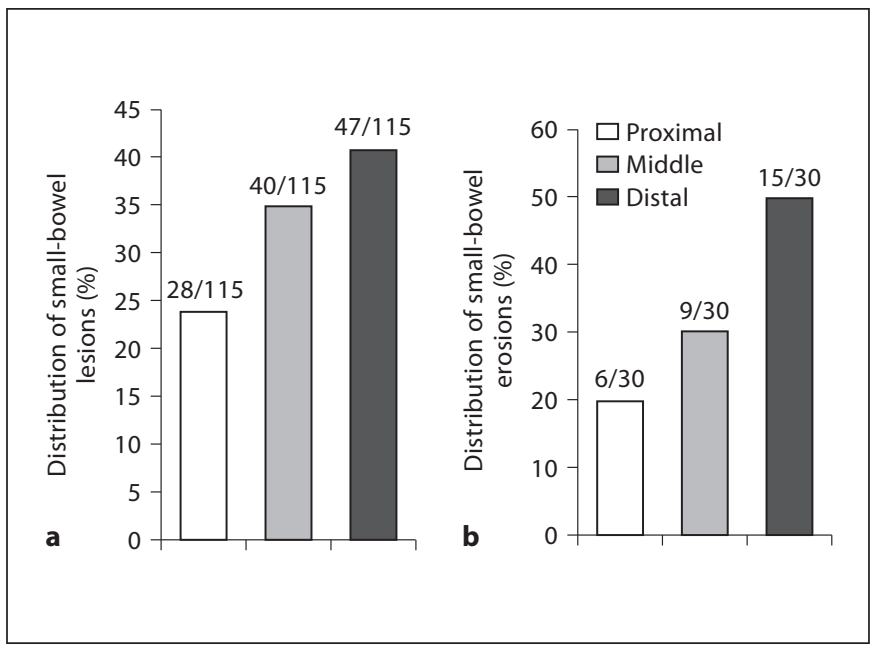

Fig. 6. a Distribution of the small-bowel lesions in the UC group; 28 of the 115 small-bowel lesions (25\%) were located in the proximal part, $40(34 \%)$ in the middle part, and $47(41 \%)$ in the distal part of the small intestine. $\mathbf{b}$ Distribution of small-bowel erosions in the UC group; 6 of the 30 erosions (20\%) were located in the proximal part, $9(30 \%)$ in the middle part, and $15(50 \%)$ in the distal part of the small intestine.

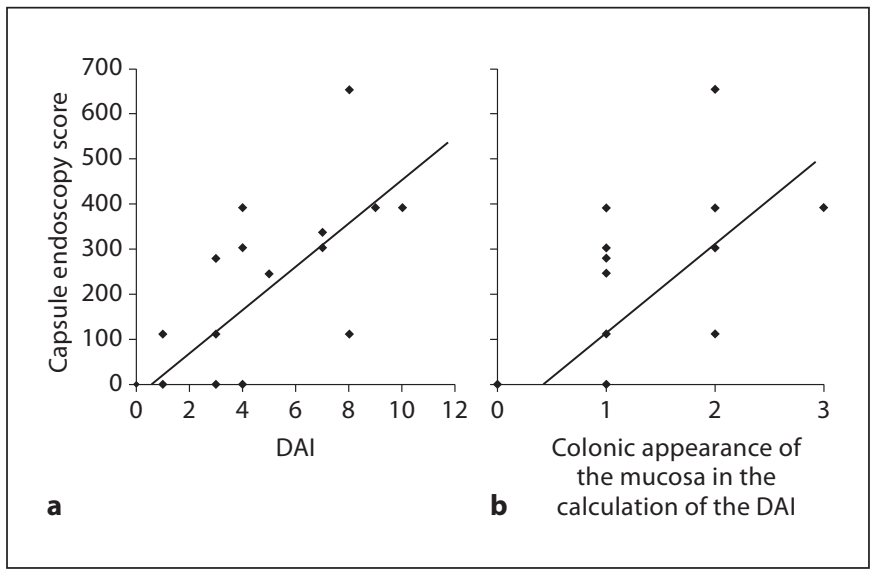

Fig. 7. a Correlation between the capsule endoscopy score and the DAI $(r=0.718, p<0.001)$. b Correlation between the capsule endoscopy score and the score for the colonic appearance of the mucosa estimated for calculation of the DAI $(r=0.554, p=0.007)$.

$0.718, \mathrm{p}<0.001$ ), as well as between the capsule-endoscopic score and the score for the colonic appearance of the mucosa estimated for calculation of the DAI $(\mathrm{r}=$ $0.554, \mathrm{p}=0.007)$. 

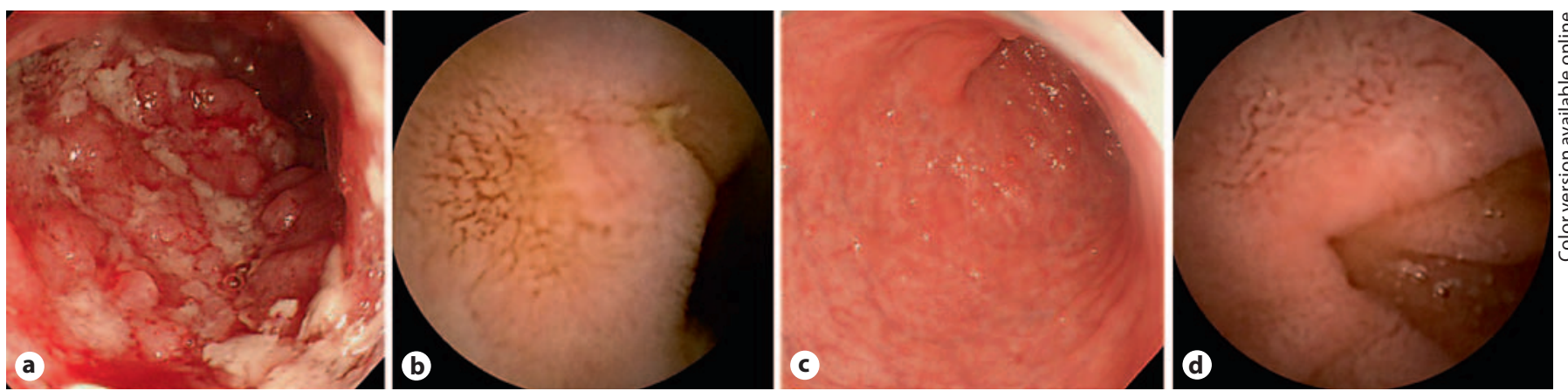

Fig. 8. a Colonoscopic findings in a first-attack UC patient before treatment. b Capsule endoscopy findings of the same patient before treatment. c Colonoscopic findings in this patient after treatment. d Capsule-endoscopic findings of the same patient after treatment.

Table 2. Comparison of the capsule endoscopy score for small-bowel inflammatory changes in the two groups

\begin{tabular}{|c|c|c|c|}
\hline & UC group & Control group & $\mathrm{p}$ value \\
\hline Median capsule endoscopy score (range) & $112(0-654)$ & $0(0-112)$ & $<0.001$ \\
\hline \multicolumn{4}{|c|}{ Categories of small-bowel mucosal inflammatory changes } \\
\hline Normal or clinically insignificant change $(<135)$ & $14 / 23(61 \%)$ & $23 / 23(100 \%)$ & 0.015 \\
\hline Mild change $(135 \leq$ score $<790)$ & $9 / 23(39 \%)$ & $0 / 23(0 \%)$ & 0.015 \\
\hline Moderate or severe change $(\geq 790)$ & $0 / 23(0 \%)$ & $0 / 23(0 \%)$ & - \\
\hline
\end{tabular}

\section{Capsule-Endoscopic Findings before and after}

Treatment in Previously Untreated Patients with

First-Attack UC

The present study included 8 patients with first-attack UC who had no history of previous treatment for UC. Capsule-endoscopic examination revealed small-bowel lesions in 7 of these untreated UC patients. Treatment with mesalazine and/or prednisolone resulted in remission in all of the 7 patients. A follow-up capsule endoscopy was performed in these patients after remission was achieved. Improvement of the small-bowel lesions along with improvement of the patients' symptoms and colonoscopic findings was noted in these patients (fig. 8a-d). The capsule endoscopy score and DAI also improved with treatment in these patients (table 3).

\section{Clinical Course of the UC Patients after the}

Capsule-Endoscopic Examination and Pathology of

the Small-Bowel Erosions

The mean follow-up period of the UC patients after capsule endoscopy was $12.6 \pm 4.6$ months. In none of the subjects was the diagnosis of UC changed during the follow-up period into Crohn's disease, Behçet's disease, or other disease. Double-balloon endoscopy was performed
Table 3. Comparison of the DAI and capsule endoscopy score measured before and after treatment in patients with first-attack UC

\begin{tabular}{lllll}
\hline $\begin{array}{llll}\text { Patient } \\
\text { No. }\end{array}$ & \multicolumn{2}{l}{ Before treatment } & & \multicolumn{2}{l}{ After treatment } \\
\cline { 5 - 6 } \cline { 5 - 5 } \cline { 5 - 5 } & DAI & $\begin{array}{c}\text { capsule endos- } \\
\text { copy score }\end{array}$ & & $\begin{array}{l}\text { DAI } \\
\text { capsule endos- } \\
\text { copy score }\end{array}$ \\
\hline 1 & 4 & 255 & 2 & 112 \\
4 & 9 & 393 & 1 & 112 \\
12 & 8 & 654 & 2 & 337 \\
15 & 3 & 112 & 1 & 0 \\
16 & 8 & 112 & 1 & 8 \\
18 & 3 & 280 & 0 & 0 \\
21 & 4 & 0 & 1 & 0 \\
23 & 7 & 337 & not administered \\
\hline
\end{tabular}

DAI $=$ Disease activity index according to Sutherland's criteria.

in 2 patients who were found to have small-bowel erosions, to explore the small intestine, with biopsy of the small-bowel erosions. Cryptitis, crypt abscesses, and lymphoplasmacytic infiltration of the lamina propria mucosae were seen, while there were no granulomas, in either group of patients (data not shown). 


\section{Discussion}

This is the first capsule-endoscopic study conducted to examine the small-bowel findings in UC patients as compared with those in healthy volunteers. We found a significantly higher frequency of small-bowel lesions in UC patients as compared with that in the control healthy volunteers. Similarly, the total number of small-bowel lesions and number of erosions were significantly higher in the UC group as compared with those in the control group.

It is well known that UC is often associated with extraintestinal manifestations. Previous studies have reported that extraintestinal manifestations occur in 51.5\% of patients with UC [19]. UC is considered to be a multifactorial polygenic chronic inflammatory disease that predominantly affects the gastrointestinal system, with the potential also for systemic involvement, such as of the biliary tract, joints, skin and eyes [7-9]. Moreover, gastroduodenal lesions of UC have recently been reported, in addition to backwash ileitis and postcolectomy pouchitis [1-6]. It is thus not surprising that UC patients were also found to have small-bowel lesions, including reddened lesions and erosions, in this study.

Therapy with mesalazine, sulfasalazopyrine and prednisolone has been reported to be effective for the upper gastrointestinal lesions of UC, whereas UC-associated gastroduodenitis has been shown to be refractory to antisecretory therapy (i.e. histamine $\mathrm{H} 2$ receptor antagonists, proton pump inhibitors, etc.) $[3,5,20]$. This suggests that these gastroduodenal lesions observed in UC patients do not have a peptic basis, but represent UC-associated lesions. In this study, we performed CE before and after treatment in patients with previously untreated first-attack UC. Small-bowel lesions observed before the treatment were found to have resolved following treatment with mesalazine and/or prednisolone, similar to the case for UC-associated gastroduodenitis, which has previously been reported to be responsive to this therapy. Moreover, almost all of the patients with first-attack UC (7 of 8) in this study had small-bowel lesions. In addition, histopathologic examination of the small-bowel erosions in UC showed cryptitis, crypt abscesses, and lymphoplasmacytic infiltration of the lamina propria mucosae. The findings were similar to the pathological findings of the colonic lesions in UC, including absence of granulomas. These findings suggest that the small-bowel lesions observed by capsule endoscopy in the UC patients in this study were all related to the UC.

The etiopathogenesis of the small-bowel lesions associated with UC is unknown; however, several mecha- nisms have been proposed based on the results of previous clinical studies of gastrointestinal lesions associated with UC and postcolectomy pouchitis. The efficacy of antibiotics and probiotics against pouchitis suggests that bacteria may play an important role in the inflammation [21]. In addition, it has been hypothesized that molecular mimicry between epithelial protein and bacterial proteins may contribute to the pathogenesis of UC [22]. The recent advances in the understanding of the pathogenesis of inflammatory bowel disease suggest that chronic inflammation is due to the aggressive cellular immune responses to a subset of luminal bacteria [23, 24]. From these reports, it was speculated that the small-bowel lesions associated with UC could possibly develop as a result of dysregulated immune responses to bacterial antigens in genetically susceptible hosts and subsequent excessive autoimmune reactions to the small-bowel epithelium, possibly via memory $\mathrm{T}$ cells recruited from the small-intestinal mucosa, as demonstrated in a previous study of the colorectal lesions [25]. Intestinal bacterial flora are likely poor in the jejunum, but abundant in the ileum [26]. In our study, the number of small-bowel lesions detected tended to increase from the proximal to the distal intestine. These results suggest that intestinal bacteria may play an important role in the pathogenesis of the small-bowel lesions associated with UC.

The present study had some limitations. First, sufficient pathological proof was not obtained to indicate that the small-bowel lesions detected in the patients with UC were indeed UC-associated lesions. On the other hand, there are no specific pathological findings of UC. Cryptitis, crypt abscesses and lymphoplasmacytic infiltration of the lamina propria mucosae are seen in UC, but these are not specific diagnostic findings [27]. Furthermore, considering that almost all of previously untreated patients with first-attack UC in this study had small-bowel lesions, the small-bowel lesions observed were speculated to be UC-associated lesions. Second, although there were no patients who had findings consistent with Crohn's disease, there was the possibility that the UC patients participating in this study included patients with indeterminate colitis (IC) or inflammatory bowel disease-type unclassified (IBDU). It has been reported that a clear distinction between Crohn's disease and UC cannot be made in $10-15 \%$ of patients with inflammatory bowel disease (IBD). The term IC or IBDU is used for such patients who present with divergent clinical, endoscopic and histological features $[28,29]$. Diagnosis of UC in this study was based on the typical endoscopic and histologic findings, after exclusion of other diseases (e.g. infectious colitis, 
ischemic colitis, radiation colitis, collagenous colitis, microscopic colitis, and drug-induced colitis) [14, 15]; however, it has been reported that the diagnosis of IBD can sometimes change during long-term observation. In a recent report, among 18 IBDU/IC patients who underwent capsule endoscopy, 7 were diagnosed as having Crohn's disease [30]. Even if some of IBDU or IC patients were included in this study, the frequency of small-bowel lesions was still remarkably high. Third, anti-Saccharomyces cerevisiae mannan antibodies (ASCA) and perinuclear antineutrophil cytoplasmic autoantibodies (pANCA) have been proposed to be clinically useful as adjunctive tools for establishing the diagnosis of IBD and for differentiating between Crohn's disease and UC [31]; however, we did not examine these markers, because ASCA is not available for use in Japan. Also, these markers are not included in the diagnostic criteria of UC in Japan, and are therefore not usually checked for in routine practice. All of the UC patients in this study showed typical clinical symptoms of UC and their endoscopic findings were also typical of UC. Moreover, patients with findings suggestive of Crohn's disease, such as gastrointestinal strictures, fistulae and abscesses, were potentially excluded. We propose to continue this investigation, and that issue is going to the next research agenda. Fourth, the UC patients enrolled in this study were almost in remission and had only mild disease activity. It is unknown whether the disease activity of UC might be related to the incidence of gastroduodenitis associated with UC and backwash ileitis [32, 33]. On the other hand, it has been reported that extraintestinal manifestations such as those related to the joints, skin and eyes are associated with UC activity in most cases [34]. In this study, the capsule endoscopy score for small-bowel mucosal inflammation was correlated with the UC-DAI. The frequency of small-bowel lesions in severe UC patients remains unknown, and further studies including severe UC patients are necessary.

In conclusion, this study suggests that small-bowel pathologies exist at a high frequency in UC patients. UC is a chronic inflammatory bowel disease that may, in addition to predominantly affecting the colon, also involve the small bowel. The severity of the small-bowel mucosal inflammatory changes in UC patients was related to the UC disease activity. Further extensive studies are required for a clearer understanding of the pathogenesis of the small-bowel lesions in UC and also of the clinical significance of UC-associated small-bowel lesions.

\section{Disclosure Statement}

None of the authors disclosed any financial relationships relevant to this publication.

\section{References}

1 Thompson JW 3rd, Bargen JA: Ulcerative duodenitis and chronic ulcerative colitis: report of two cases. Gastroenterology 1960;38: $452-455$.

2 Manier JW, Reyes CN Olcen TG: Ulcerative colitis and ulcerative gastritis. Am J Gastroenterol 1972;58:502-507.

-3 Ikeuchi H, Hori K, Nishigami T, Nakano H, Uchino M, Nakamura M, Nakamura M, Kaibe N, Noda M, Yanagi H, Yamamura T: Diffuse gastroduodenitis and pouchitis associated with ulcerative colitis. World J Gastroenterol 2006;12:5913-5915.

-4 Annese V, Caruso N, Bisceglia M, Lombardi G, Clemente R, Modola G, Modola G, Tardio B, Villani MR, Andriulli A: Fatal ulcerative panenteritis following colectomy in a patient with ulcerative colitis. Dig Dis Sci 1999;44: 1189-1195.

5 Rubenstein J, Sherif A, Appelman H, Chey WD: Ulcerative colitis associated enteritis: is ulcerative colitis always confined to the colon? J Clin Gastroenterol 2004;38:46-51.
6 Tobin JM, Sinha B, Ramani P, Saleh AR, Murphy MS: Upper gastrointestinal mucosal disease in pediatric Crohn disease and ulcerative colitis: a blinded, controlled study. J Pediatr Gastroenterol Nutr 2001;32:443-448.

7 Rothfuss KS, Stange EF, Herrlinger KR: Extraintestinal manifestations and complications in inflammatory bowel diseases. World J Gastroenterol 2006;12:4819-4831.

8 Larsen S, Bendtzen K, Nielsen OH: Extraintestinal manifestations of inflammatory bowel disease: epidemiology, diagnosis, and management. Ann Med 2010;42:97-114.

$\checkmark 9 \mathrm{Wu}$ CH, Wong JM, Hsieh SC, Yu CL: An unusual case of ulcerative colitis with concurrent extraintestinal manifestations of primary sclerosing cholangitis, thromboembolism, hemolytic anemia, and hemochromatosis. J Microbiol Immunol Infect 2005;38:224-229.
10 Calabrese C, Fabbri A, Gionchetti P, Rizzello F, Morselli C, Liguori G, Liguori G, Poggioli G, Campieri M, Di Febo G: Controlled study using wireless capsule endoscopy for the evaluation of the small intestine in chronic refractory pouchitis. Aliment Pharmacol Ther 2007;25:1311-1316.

11 Iddan G, Meron G, Glukhovsky A, Swain P: Wireless capsule endoscopy. Nature 2000; 405:417.

12 Rossini FP, Pennazio M: Small-bowel endoscopy. Endoscopy 2002;34:13-20.

13 Kornbluth A, Sachar DB; Practice Parameters Committee of the American College of Gastroenterology. Ulcerative colitis practice guidelines in adults: American College Of Gastroenterology, Practice Parameters Committee. Am J Gastroenterol 2010;105: 500.

14 Carter MJ, Lobo AJ, Travis SP, IBD Section, British Society of Gastroenterology: Guidelines for the management of inflammatory bowel disease in adults. Gut 2005;54:566. 
15 Sutherland LR, Martin F, Greer S, Robinson M, Greenberger N, Saibil F, Saibil F, Martin T, Sparr J, Prokipchuk E, Borgen L: 5-Aminosalicylic acid enema in the treatment of distal ulcerative colitis, proctosigmoiditis, and proctitis. Gastroenterology 1987;92: 1894-1898.

-16 Mow WS, Lo SK, Targan SR, Dubinsky MC, Treyzon L, Abreu-Martin MT, Abreu-Martin MT, Papadakis KA, Vasiliauskas EA: Initial experience with wireless capsule enteroscopy in the diagnosis and management of inflammatory bowel disease. Clin Gastroenterol Hepatol 2004;2:31-40.

$\checkmark 17$ Mehdizadeh S, Chen G, Enayati PJ, Cheng DW, Han NJ, Shaye OA, Shaye OA, Ippoliti A, Vasiliauskas EA, Lo SK, Papadakis KA: Diagnostic yield of capsule endoscopy in ulcerative colitis and inflammatory bowel disease of unclassified type (IBDU). Endoscopy 2008;40:30-35

-18 Gralnek IM, Defranchis R, Seidman E, Leighton JA, Legnani P, Lewis BS: Development of a capsule endoscopy scoring index for small-bowel mucosal inflammatory change. Aliment Pharmacol Ther 2008;27: 146-154 [PMID: 17956598].

19 Mendoza JL, Lana R, Taxonera C, Alba C, Izquierdo S, Díaz-Rubio M: Extraintestinal manifestations in inflammatory bowel disease: differences between Crohn's disease and ulcerative colitis. Med Clin (Barc) 2005; 125:297-300.
20 Sasaki M, Okada K, Koyama S, Yoshioka U, Inoue H, Fujiyama Y, Fujiyama Y, Bamba T: Ulcerative colitis complicated by gastroduodenal lesions. J Gastroenterol 1996;31:585589.

21 Shen B, Fazio VW, Remzi FH, Lashner BA Clinical approach to diseases of ileal pouchanal anastomosis. Am J Gastroenterol 2005; 100:2796-2807.

22 Kovvali G, Das KM: Molecular mimicry may contribute to pathogenesis of ulcerative colitis. FEBS Lett 2005;579:2261-2266.

23 Kucharzik T, Maaser C, Lügering A, Kagnoff M, Mayer L, Targan S, Targan S, Domschke $\mathrm{W}$ : Recent understanding of IBD pathogenesis: implications for future therapies. Inflamm Bowel Dis 2006;12:1068-1083.

24 Sands BE: Inflammatory bowel disease: past, present, and future. J Gastroenterol 2007;42: $16-25$.

-25 Berrebi D, Languepin J, Ferkdadji L, Foussa A, De Lagausie P, Paris R, Emilie D, Mougenot JF, Cezard JP, Navarro J, Peuchmaur M Cytokines, chemokine receptors, and homing molecule distribution in the rectum and stomach of pediatric patients with ulcerative colitis. J Pediatr Gastroenterol Nutr 2003;37: 300-308.

26 Hao WL, Lee YK: Microflora of the gastrointestinal tract: a review. Methods Mol Biol 2004;268:491-502.

27 Jenkins D, Balsitis M, Gallivan S, Dixon MF, Gilmour HM, Shepherd NA, Theodossi A, Williams GT: Guidelines for the initial biopsy diagnosis of suspected chronic idiopathic inflammatory bowel disease: the British Society of Gastroenterology Initiative. J Clin Pathol 1997;50:93-105.
28 Mitchell PJ, Rabau MY, Haboubi NY: Indeterminate colitis. Tech Coloproctol 2007;11: 91-96.

29 Silverberg MS, Satsangi J, Ahmad T, et al: Toward an integrated clinical, molecular and serological classification of inflammatory bowel disease: report of a Working Party of the 2005 Montreal World Congress of Gastroenterology. Can J Gastroenterol 2005; 19(suppl A):5-36

>30 Lopes S, Figueiredo P, Portela F, Freire P, Almeida N, Lérias C, Gouveia H, Leitão MC: Capsule endoscopy in inflammatory bowel disease type unclassified and indeterminate colitis serologically negative. Inflamm Bowel Dis 2010;16:1663-1668.

>31 Reumaux D, Sendid B, Poulain D, Duthilleul P, Dewit O, Colombel JF: Serological markers in inflammatory bowel diseases. Best Pract Res Clin Gastroenterol 2003;17:19-35.

32 Hori K, Ikeuchi H, Nakano H, Uchino M, Tomita T, Ohda Y, Hida N, Matsumoto T, Fukuda Y, Miwa H: Gastroduodenitis associated with ulcerative colitis. J Gastroenterol 2008;43:193-201.

33 Yamamoto T, Maruyama Y, Umegae S, Matsumoto K, Saniabadi AR: Mucosal inflammation in the terminal ileum of ulcerative colitis patients: endoscopic findings and cytokine profiles. Dig Liver Dis 2008;40:253259.

34 Agrawal D, Rukkannagari S, Kethu S: Pathogenesis and clinical approach to extraintestinal manifestations of inflammatory bowel disease. Minerva Gastroenterol Dietol 2007; 53:233-248. 